trẻ chủ yếu qua ti vi $(73,0 \%)$ và internet $(49,5 \%)$, tỷ lệ nhận thông tin từ nhân viên y tê (26\%), nhận được tờ rơi cung cấp thông tin về nhiễm độc chì cho trẻ chỉ chiếm tỷ lệ thấp dưới $1 \%$. Kết quả này và phù hợp với sư triển của công nghệ thông tin hiện đại (đa số các hộ gia đình đều có ti vi và tiếp cận được internet). Tuy nhiên kết quả này cũng phản ánh rằng có thể tại Đa Hội chưa có hoặc ít triển khai hoặc triển khai chưa hiệu quả các hoạt động truyền thông về phòng chống nhiễm độc chì cho người dân. Đây có thể là lý do giải thích tại sao tỷ lệ người trả lời đúng các câu hỏi về kiển thức liên quan đến phòng tránh nhiễm độc chì cho trẻ trong nghiên cứu còn thấp.

\section{KẾT LUÂ̂N}

- Người dân tai môt làng nghề thuộc tỉnh Bắc Ninh đã có một số kiến thức cơ bản về phòng chống nhiễm độc chì cho trẻ nhưng còn hạn chế.

- Điểm kiến thức trung bình của nhóm người chăm sóc trẻ là $3,7 \pm 1,2$ điểm, của nhóm trẻ em 11-14 tuổi là 3,5 $\pm 0,9$ điểm. Tỷ lệ người chăm sóc trẻ có kiến thức đạt chiếm $64,2 \%$, tỷ lệ này ở nhóm trẻ em 11-14 tuổi tham gia nghiên cứu là 46,8\%.

\section{KHUYẾN NGH!}

Các tác giả khuyến nghị cần tăng cường triển khai các hoạt động truyền thông giáo dục sức khỏe dưới nhiều hình thức như tờ rơi, phát thanh trên loa, truyên thông trực tiếp tại trạm y tế và trường học, tư vấn/ giáo dục nhóm.... nhằm nâng cao kiến thức và thay đổi thái độ và thực hành về phòng tránh nhiễm độc chì cho trẻ em tại địa điểm nghiên cứu.

\section{TÀI LIẸU THAM KHẢO}

1. Moawad E.M., Badawy N.M. and Manawill M. (2016), "Environmental and Occupational Lead Exposure Among Children in Cairo, Egypt: A Community-Based Cross-Sectional Study", Medicine (Baltimore). 95(9).

2. WHO (2010), Childhood lead poisoning, WHO Document Production Services, Geneva, Switzerland.

3. Mahon I (1997), "Caregivers' knowledge and perceptions of preventing childhood lead poisoning", Public Health Nurs. 14(3), 169-182.

4. Tanya Haman, Angela Mathee and Andre Swart (2015), "Low Levels of Awareness of Lead Hazards among Pregnant Women in a High RiskJohannesburg Neighbourhood", Int J Environ Res Public Health. 12(12), 15022-15027.

5. Farrah Baara (2012), Best Practices for Lead Poisoning Prevention in Urban Bangkok Communities, Chulalongkorn University, Worcester Polytechnic Institute. (22)

6. James R. Roberts, et al. (2012), "Are Children Still at Risk for Lead Poisoning?", Clinical Pediatrics 52(2), 125-130.

7. Bustamante and Trepka Pekovic. V. (2005), "Haitian Caregivers' Knowledge and Attitudes Regarding Childhood Lead Poisoning", Miami-Dade County. 6.

\title{
KẾT QUẢ SớM PHẪU THUẬT NộI SOI ĐIỀU TRỊ GIST DẠ DÀY TẠI BỆNH VIỆN K
}

\section{TÓM TẮT}

Mục tiêu: Nghiên cứu này nhằm đánh giá kết quả sớm phẫu thuật nội soi điêu trị GIST da dày tạibệnh viên K. Phương pháp nghiên cứu: Hồi cứu mồ tả cắt ngang tất cả các bệnh nhân được chẩn đoán GIST da dày và điêu trị bằng phẩu thuật nội soi từ tháng 01/2018 đến tháng 12/2020. Kết quả: Có 37 bệnh nhân đủ tiêu chuẩn nghiên cứu với khối u kích thước từ 2 đến $9 \mathrm{~cm}$, trong đó 35 bệnh nhân $(94,6 \%)$ có giải phẩu bênh là u tế bào hình thoi, 2 bệnh nhân $(5,4 \%)$ giải phẫu bệnh u tế bào dạng biểu mô, thời gian mổ

${ }^{1}$ Trường Đại học Y Hà Nội

${ }^{2}$ Bềnh viện $K$

Chịu trách nhiệm chính: Hoàng Anh

Email: drhoanganh@hmu.edu.vn

Ngày nhận bài: 8.6.2021

Ngày phản biên khoa học: 30.7.2021

Ngày duyệt bài: 9.8 .2021
Hoàng Anh', Kim Văn Vụ̂, Phạm Trung Thông ${ }^{2}$, Nguyễn Tiến Trung ${ }^{2}$ trung bình $59,08 \pm 25,17$ phút, thời gian hậu phẫu

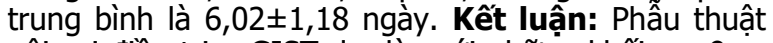
nội soi điều trị u GIST da dày với những khối u $<9 \mathrm{~cm}$ là an toàn, hiệu quả và có thể thực hiện ở những trung tâm lớn, phẫu thuật viên kinh nghiệm.

Tư khóa: Phẫu thuật nội soi điêu trị GIST dạ dày.

\section{SUMMARY}

\section{EARLY RESULTS OF LAPAROSCOPIC RESECTION OF GASTROINTESTINAL STROMAL IN K HOSPITAL}

Objectives: The aim of this study is to present initial results of laparoscopic resection of gastrointestinal stromal in K hospital. Methods: A retro-observational of all patients whom had been diagnosised GIST and treated by laparoscopic resection from 01/2018 to 12/2020. Results: 37 patients were identified whose tumor's size from 2 to $9 \mathrm{~cm}$, Histology study showed spindle in 35 patients $(94,6 \%)$ and epithelioid in 2 patients(5,4\%), medium 
surgical time is $59,08 \pm 25,17$ mins, medium time of operative period is $6,02 \pm 1,18$ days. Conclusions: Laparoscopic resection of GIST which tumor's size is less than $9 \mathrm{~cm}$ is effective, safe and can be performed in hightech medical center with experienced surgeons.

Keywords: Laparoscopic resection of GIST

\section{I. ĐặT VẤN ĐỀ}

U mô đệm đường tiêu hóa (GIST gastrointestinal stromal tumour) là khối utrung mô thuộc mô đệm đường tiêu hóa, u có tổ chức liên kết, nguồn gốc xuất phát từ tế bào kẽ Cajal nằm trong lớp cơ. GIST chiếm tỷ lệ ít hơn $1 \%$ các trường hợp u đường tiêu hóa và $5 \%$ các sarcoma. Hầu hết nghiên cứu cho thãy tỷ lệ mắc GIST từ 10-15/1 triệu dân mối năm với độ tuổi trung bình là 60 . GIST có thể xuất hiện tại tất cả vị trí của ống tiêu hoá, hay gặp nhất tại dạ dày (70\%), ruột non $\left.(20 \%)\left[{ }^{1}\right],{ }^{2}\right]$

GIST gồm 3 loại tế bào khác nhau: tế bào hình thoi $(70 \%)$, tể bào dạng biểu mô $(10 \%)$ và dạng hỗn hợp (20\%). Về sinh học phân tử, GIST được xác định dựa vào sự có mặt của kháng thể CD117 với giá trị dương tính tới 95-97\%[3]. Tuy vậy, vẫn có $3-5 \%$ trường hợp âm tính với CD117, vì vậy để phân biệt với các u trung mô có hình thái học gối nhau, người ta sử dụng 1 số kháng thể khác như DOG1, CD34, Desmin, SMA, S100, CK.

GIST được phân độ ác tính chủ yếu dựa vào 2 chỉ số: kích thước của u và chỉ số nhân chia với 4 mức độ: rất thấp - thấp - cao - rất cao. Ngoài ra còn các yếu tố: vị trí u, tính nguyên vẹn của u, chỉ số MIB-1 $\left[{ }^{4}\right]$

Phương pháp điều trị GIST chủ yếu vẫn là phầu thuật cắt bỏ u với diện cắt âm tính và tránh làm võ u. Imatinib được chỉ định cho những bệnh nhân được đánh giá nguy cở cao - rất cao

Tại bệnh viện $\mathrm{K}$ đã phẫu thuật nội soi cắt $\mathrm{u}$ GIST từ nhiều năm gần đây nhưng chưa có báo cáo nào về kết quả. Do đó chúng tôi thực hiện nghiên cứu này nhằm đánh giá kết quả sớm của phẫu thuật nội soi điều trị GIST dạ dày tại bệnh viện $\mathrm{K}$.

Mục tiêu nghiên cứu: Nghiên cứu này nhằm đánh giá kết quả sớm của phấu thuật nội soi điều trị GIST dạ dày tại bệnh viện K trung ương.

\section{II. ĐỐI TƯƠNG VÀ PHƯƠNG PHÁP NGHIÊN CỨU} Thời gian nghiên cứu: tháng 01/2018 đên tháng 12/2020

Địa điểm nghiên cứu: bệnh viện $\mathrm{K}$

Tiêu chuẩn lựa chọn: bệnh nhần được chẩn đoán u mô đệm dạ dày (có bằng chứng giải phẫu bệnh/ hoá mổ miễn dịch), được điêu trị bằng phẫu thuật nội soi (bao gồm phẫu thuật nội soi thành công và chuyển mổ mở), hồ sơ bệnh án đầy đủ

Thiết kế nghiên cứu: hồi cứu mô tả cắt ngang

Cỡ mẫu: Tất vả bệnh nhân đủ tiêu chuẩn nghiên cứu trong thời gian nghiên cứu

\section{KẾT QUẢ NGHIÊN CỨU}

37 bệnh nhân đủ tiêu chuẩn lựa chọn trong thời gian nghiên cứu

Độ tuổi trung bình của bệnh nhân khi được phẫu thuật là $53,43 \pm 13,46$ tuổi (từ 25 đên 82 tuổi) với $62,2 \%$ bệnh nhân từ 41 đên 60 tuổi, trong đó có 21 trường hợp nữ giới, 16 trường hợp nữ giới, tỷ lệ nữ/nam 1,31/1

\section{Bảng 1: Phân bố bệnh nhân theo độ tuổi - giới tính}

\begin{tabular}{|c|c|c|c|c|c|c|}
\hline \multirow{2}{*}{$\begin{array}{c}\text { Giới tính } \\
\text { Nhóm tuổi } \\
\end{array}$} & \multicolumn{2}{|c|}{ Nam } & \multicolumn{2}{|c|}{ Nữ } & \multicolumn{2}{|c|}{ Tống } \\
\hline & $\mathbf{n}$ & $\%$ & $\mathbf{n}$ & $\%$ & $\mathbf{n}$ & $\%$ \\
\hline$<20$ tuối & 0 & 0 & 0 & 0 & 0 & 0 \\
\hline Từ 21 - 40 tuối & 2 & 5,4 & 4 & 10,8 & 6 & 16,2 \\
\hline Từ $41-60$ tuối & 11 & 29,7 & 12 & 32,5 & 23 & 62,2 \\
\hline Tứ $60-80$ tuối & 3 & 8,1 & 4 & 10,8 & 7 & 18,9 \\
\hline$>80$ tuối & 0 & 0 & 1 & 2,7 & 1 & 2,7 \\
\hline Tống & 16 & 43,2 & 21 & 56,8 & 37 & 100 \\
\hline
\end{tabular}

Phần lớn bệnh nhân nhập viện vì triệu chứng đau bụng thượng vị kéo dài (27/37 bệnh nhân, chiếm $73 \%$ ), các triệu chứng khác ít gặp hơn như xuất huyết tiêu hóa (2 bệnh nhân- $5,4 \%$ ), sờ thấy $u$, sút cân,... hiếm gặp, 7 bệnh nhân $(18,9 \%)$ tình cờ phát hiện bệnh. Tất cả bệnh nhân được nội soi dạ dày, siểu âm ổ bụng và chụp cắt lớp vi tính có tiêm thuốc cản quang (CLVT) để chẩn đoán và đánh giá khối u.

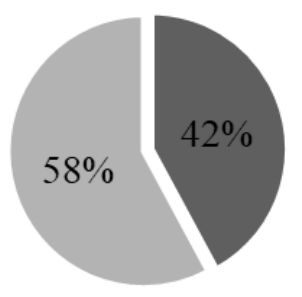

- Ranh Giới rõ " Ranh giới không rõ 


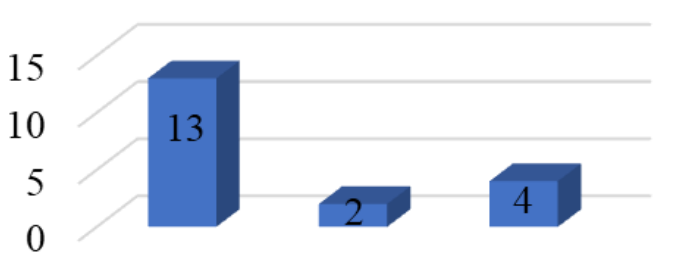

Giảm âm Tăng âm Hỗn hợp âm

\section{Biểu đồ 1: Hình thái GIST trên siêu âm}

Tất cả bênh nhân được siêu âm ổ bunng, 19 trường hợp $(51,4 \%)$ phát hiện thây u. Trong đó 8 trường hợp $(42,1 \%)$ thấy rõ ranh giới $u, 11$ trường hợp $(57,9 \%)$ không rõ ranh giới. Có 13 trường hợp $(68,4 \%)$ có hình ảnh khối giảm âm trên siêu âm, 4 trường hợp $(21,1 \%)$ hình ảnh âm hỗn hợp và 2 trường hợp (10,5\%) tăng âm.

Bảng 2: Hình ảnh chup cắt lớp vi tính ổ bung

\begin{tabular}{|c|c|c|c|}
\hline \multicolumn{2}{|c|}{ Tính chất trên cắt lớp vi tính } & $\mathbf{n}$ & $\%$ \\
\hline \multirow{2}{*}{$\begin{array}{l}\text { Hình } \\
\text { thái }\end{array}$} & Đặc & 27 & 81,8 \\
\hline & Hồn hợp & 6 & 18,2 \\
\hline \multirow{3}{*}{$\begin{array}{l}\text { Ngấm } \\
\text { thuốc }\end{array}$} & Ngấm ít & 8 & 24,2 \\
\hline & Ngấm mạnh & 25 & 75,8 \\
\hline & Không ngấm & 0 & 0 \\
\hline \multirow{2}{*}{$\begin{array}{l}\text { Ranh } \\
\text { giới }\end{array}$} & Rõ & 25 & 75,8 \\
\hline & Không rõ & 8 & 24,2 \\
\hline \multirow{3}{*}{$\begin{array}{l}\text { Xâm } \\
\text { lấn }\end{array}$} & Xâm lấn xung quanh & 1 & 3 \\
\hline & $\begin{array}{c}\text { Đè đấy nhưng không } \\
\text { xâm lấn }\end{array}$ & 7 & 21,2 \\
\hline & Không xâm lấn & 25 & 75,8 \\
\hline \multirow[b]{2}{*}{ Hạch } & Hạch to lân cận & 0 & 0 \\
\hline & $\begin{array}{c}\text { Không thấy hạch to lân } \\
\text { cận }\end{array}$ & 33 & 100 \\
\hline \multirow{3}{*}{$\begin{array}{l}\text { Kích } \\
\text { thước }\end{array}$} & $<2 \mathrm{~cm}$ & 0 & 0 \\
\hline & Từ $2-5 \mathrm{~cm}$ & 24 & 72,7 \\
\hline & $>5 \mathrm{~cm}$ & 9 & 27,3 \\
\hline
\end{tabular}

Tỷ lệ phát hiện u trên CLVT 89,2\% (33/37

ca). Hình ảnh tổn thương thường găp là khối đăc (27/33, chiếm $81,8 \%)$, ngấm thuốc mạnh $(25 / 33$ - 75,8\%), ranh giới rõ $(25 / 33-75,8 \%)$, không xâm lấn cơ quan xung quanh $(25 / 33-75,8 \%)$, không có hạch to lân cận $(100 \%)$, kích thước từ 2 đến $5 \mathrm{~cm}(24 / 33$, chiếm $72,7 \%)$

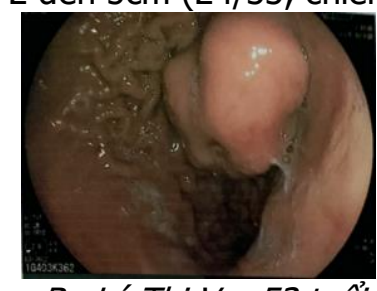

Bn Lý Thi V- 53 tuôi

\section{Hinh 1: hình ảnh nôi soi và siêu âm nối soi của GIST da dày}

Nội soi dạ dày phát hiện thấy tổn thương $32 / 37$ trường hợp chiếm tỉ lệ 86,5\%, với21 trường hợp $(56,8 \%)$ u đè đẩy từ ngoài vào, 6 trường hợp $(16,2 \%)$ tổn thương loét dạ dày, 5 bệnh nhân có hình ảnh khối đẩy lồi từ ngoài vào kèm loét ở đỉnh u $(13,5 \%) .9$ trường hợp $(24,3 \%)$ sinh thiết qua nội soi ống mềm,kết quả âm tính 89,9\%, 1 trường hợp dương tính (11,1\%).11/37 bệnh nhân $(29,7 \%)$ làm siêu âm nội soi dạ dày với tỷ lệ $100 \%$ tổn thương nằm ở lớp 4 của thành ống tiêu hoá tương ứng với lớp cơ.

Đánh giá trong mổ: đa số u tại thân vị ( 26 trường hợp, chiếm 70,3\%), 1 trường hợp $(2,7 \%)$ u từ hang vị kéo dài lên thân vị. 23 bệnh nhân $(62,2 \%)$ có u phát triển ra ngoài thanh mạc. 36 trường hợp $(97,3 \%)$ được phẩu thuật nội soi cắt da dày hình chêm với các phương pháp: cắt bằng stapler 19 trường hợp $(51,4 \%), 14$ bệnh nhân $(37,8 \%)$ cắt u và khâu dạ dày qua nội soi, 3 bệnh nhân $(8,1 \%)$ cắt dạ dày hình chêm và mở nhỏ khâu dạ dày. 1 trường hợp cắt đoạn dạ dày, chiếm $2,7 \%$.

Bảng 3: Liên quan phương pháp xử lý u và vị trí u

\begin{tabular}{|c|c|c|c|c|c|}
\hline $\begin{array}{c}\text { Phương pháp xử lý } \\
\text { Vị trí u }\end{array}$ & Stapler & $\begin{array}{c}\text { Cắt dạ dày } \\
\text { hình chêm và } \\
\text { khâu tay NS }\end{array}$ & $\begin{array}{c}\text { Cắt dạ dày hình } \\
\text { chêm và mở nhỏ } \\
\text { khâu tay }\end{array}$ & $\begin{array}{c}\text { Cắt } \\
\text { đoạn } \\
\text { dạ dày }\end{array}$ & Tổng \\
\hline Dưới tâm vị & 0 & 1 & 2 & 0 & 3 \\
\hline Thân vị & 17 & 8 & 1 & 0 & 26 \\
\hline Hang vị & 2 & 5 & 0 & 0 & 7 \\
\hline Hang vị lan lên thân vị & 0 & 0 & 0 & 1 & 1 \\
\hline Tống & $\mathbf{1 9}$ & $\mathbf{1 4}$ & $\mathbf{3}$ & $\mathbf{1}$ & $\mathbf{3 7}$ \\
\hline
\end{tabular}

Thời gian mổ trung bình là $59,08 \pm 25,17$ phút, ngắn nhất là 25 phút, dài nhất là 150 phút.

Trong nghiên cứu này của chúng tôi không gặp trường hợp tai biến trong mổ và biến chứng sau mổ. Bệnh nhân ăn trở lại vào ngày hậu phẫu thứ 2-3. Trung bình thời gian nằm viện sau mổ là
$6,02 \pm 1,18$ ngày, ít nhất là 4 ngày, nhiều nhất là 9 ngày.

Giải phẫu bệnh học sau mổ: 35 trường hợp $(94,6 \%)$ có mô bênh học là u tế bào hình thoi, 2 trường hợp $(5,4 \%)$ u tế bào dạng biểu mô, không có trường hợp nào u hỗn hợp. 
Bảng 4: Mô bệnh học của các khôii u

\begin{tabular}{|c|c|c|}
\hline GPB & Số bệnh nhân & Tỷ lệ\% \\
\hline U tế bào hình thoi & 35 & $94,6 \%$ \\
\hline U dạng biếu mồ & 2 & $5,4 \%$ \\
\hline U hôn hợp & 0 & 0 \\
\hline Tống & $\mathbf{3 7}$ & $\mathbf{1 0 0} \%$ \\
\hline $29 / 37$ bềnh
\end{tabular}

29/37 bệnh nhân (78,4\%) nhuôm hoá mô miễn dịch với tỷ lê dương tính CD̉117:100\%, CD34: 96,6\%, DOG1: 100\%, SMA: 17,2\%

dich

Bảng 5: kêt quả nhuộm hoá mô miễn

\begin{tabular}{|c|c|c|c|c|c|c|}
\hline $\begin{array}{c}\text { Dấu } \\
\text { ấn }\end{array}$ & CD117 & CD34 & DOG1 & SMA & S100 & $\begin{array}{c}\text { Pesm } \\
\text { in }\end{array}$ \\
\hline $\mathrm{n}(+)$ & 29 & 28 & 29 & 5 & 0 & 0 \\
\hline$\%$ & 100 & 96,6 & 100 & 17,2 & 0 & 0 \\
\hline
\end{tabular}

\section{BÀN LUẬN}

Trong đề tài nghiên cứu của tôi bệnh nhân có độ tuổi trung bình $53,43 \pm 13,46$ tuổi, trong đó nhóm đối tượng trung niên (41-60 tuổi) hay gặp nhất chiếm tỷ lệ $62,2 \%$, tương tự như nhiều kết quả khác được ghi nhận như tác giả Đố Hùng

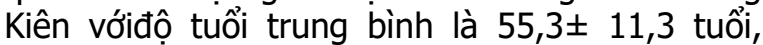
nhóm tuổi hay mắc 40-69 tuổi [ $\left.{ }^{1}\right]$

Theo nhiều tác giả nước ngoài, phần lớn GIST không có triệu chứng và được phát hiện một cách tình cờ. Theo nghiên cứu đa trung tầm của Min-Chan Kim và cộng sự trên 1057 trường hợp GISTdạ dày tại Hàn Quốc và Nhật Bản từ năm 2000 đến 2007, tỷ lệ không triệu chứng chiếm $47,5 \%\left[{ }^{5}\right]$, tuy nhiên trong nghiên cứu của chúng tôi chỉ có $18,9 \%$ trường hợp được phát hiên tình cờ không triệu chứng. Kểt quả bệnh nhẩn vào viện với triệu chứng đau bụng chiếm $73 \%$. Theo Đổ Hùng Kiên (2017) đau bụng chiếm 54,8 \% [ $\left.{ }^{1}\right]$, Xanxai Soryavong (2016) triệu chứng đau bụng chiếm $62,9 \%,\left[{ }^{6}\right], \ldots$

Do dạ dày là tạng rỗng có chứa hơi nên làm giảm đi chất lượng hình ảnh trên siêu âm chính vì vậy siêu âm ổ bụng không là sự lựa chọn tối ưu trừ khi u đạt tới kích thước đủ lớn và bệnh nhân đạt được sự chuẩn bị tiêu chuẩn: uống nước đủ để căng dạ dày. Trong nghiên cứu của chúng tôi có $51,4 \%$ bệnh nhân phát hiện $u$, thấp hơn Xanxai soryavong (2016) phát hiện trên siêu âm $78,1 \%\left[{ }^{6}\right]$. GIST biểu hiện trên siêu âm thường găp khối giảm âm, nhưng u càng có kích thước lớn càng dễ bi hoai tử trung tâm, chảy máu trong u hoặc thoái hóa nang nên trên hình ảnh siêu âm thường thây lúc này là dạng hỗn hợp âm. Trong nghiên cứu của chúng tôi hình ảnh giảm âm chiếm $68,4 \%$ (13 bệnh nhân), 21,1\% hỗn hợp âm (4 trường hợp) và tăng âm chỉ gặp ở 10,5\% (2 bệnh nhân). Trong khi nghiên cứu của Xanxai
Soryavong lại ghi nhận hình ảnh hay gặp nhất là hỗn hợp âm chiếm $\left.46,8 \%{ }^{6}\right]$ cao hơn chúng tôi. Điều này có thể được giải thích do cỡ mẫu của chúng tôi chưa đủ lớn và tỉ lệ u trên $5 \mathrm{~cm}$ của chúng tôi chỉ chiếm $24,3 \%$.

Chụp cắt lớp vi tính: có vai trò trong cơ bản đối với u mô đệm dạ dày, có giá trị cao không chỉ trong làm bilan chẩn đoán: vị trí u, kích thước u, mức độ xâm lấn cơ quan lân cận mà còn trong theo dõi, đánh giá đáp ứng điều trị và tái phát sau mổ. Trong nghiên cứu của chúng tôi, chụp cắt lớp vi tính được thực hiện ở tất cả bệnh nhẩn và giúp phát hiện được $u$ hướng tới GIST dạ dày trong $89,2 \%$ các trường hợp (33/37) với kích thước của khối u trên CLVT từ 2đến $5 \mathrm{~cm}$ chiếm tỷ lệ cao nhất $69,7 \%$. Hình ảnh tổn thương thường gặp là khối đă̆c, nhấm thuốc mạnh, ranh giới rõ, không xâm lấn cơ quan lân cận, không có hach to lân cận. Khối u có kích thước nhỏ nhất là $2 \mathrm{~cm}$, lớn nhất là $9 \mathrm{~cm}$, kết quả này tương tự như một số tác giả trong nước như Phạm Minh Hải (2008) nghiên cứu về GIST đường tiêu hóa chung $\left[{ }^{7}\right]$, Xanxai Soryavong nghiên cứu về GIST dạ dày $\left[{ }^{6}\right], \ldots$

Tổn thương của u mô đệm dạ dày trên hình ảnh nội soi thường nằm dưới niêm mạc được bao phủ bởi một lớp niêm mạc bình thường, đôi khi có thể có loét, tăng sinh mạch hay chảy máu do u chèn ép gây thiếu máu cục bộ vùng niêm mạc ở vị trí tương ứng. Tuy nhiên, hình ảnh nội soi chỉ mang tính chất gợi ý chứ không thể phân biêt được u mô đệm da dày và những tổn thương với các u lành hay ác tính khác. Do kìm sinh thiết qua nội soi thường chỉ lấy được tổ chức nông trên bề mặt nên đối với các u dưới niêm mạc như GIST việc sinh thiết xác định bản chất tổn thương gặp nhiều khó khăn và không đem lại nhiều giá trị. Nghiên cứu của chúng tôi cho kểt quả dương tính $11,1 \%$. Theo 1 số nghiên cứu của tác giả nước ngoài cho tỉ lệ sinh thiết dương tính dao động từ 17-42 \% [ $\left.{ }^{8}\right]$.

Trong 37 bệnh nhân, 29,7\% bệnh nhân được siêu âm nội soi. Các trường hợp còn lại do u đã được xác định rõ hình ảnh trên phim CLVT và đều có chỉ định phẫu thuật nên không cần thiết phải làm siêu âm nội soi.

Theo một số nghiên cứu trước thây rằng vị trí hay gặp GIST dạ dày là $1 / 3$ trên như In- Hwan Kim (2014) 49,3\%, Ki- Han Kim (2012) 58,7\%. Nghiên cứu của chúng tôi thây GIST da dày gặp nhất ở vị trí thân vị với 26 bệnh nhẩn, chiếm $70,3 \%$, tiếp theo là hang vị và dưới tâm vị, lần lượt là 7 bệnh nhân $(18,9 \%)$ và 3 bệnh nhân $(8,1 \%), 1$ bệnh nhân u hang vị lan lên thân vị. 
Điều này liên quan tới phương pháp xử lý khối u và thời gian mổ. Các khối u ở mặt trước thân vị và bờ cong lớn sẽ dễ dàng cắt dạ dày hình chêm với 1 stapler (17 bệnh nhân - 43,5\%), thời gian phẫu thuật ngắn. Các khối u vùng hang vị, tâm vị, bờ cong nhỏ hoặc mặt sau dạ dày cần nhiều thời gian để phẫu tích và xử lý. 3 bệnh nhân u dưới tâm vị, chúng tôi phải cắt dạ dày hình chêm và khâu tay qua nội soi/ mở nhỏ. 1 bệnh nhân u hang vị lan lên thân vị, u to, khó đảm bảo lưu thông tiêu hoá qua hang vị nếu cắt hình chêm, do đó chúng tôi quyết định cắt đoạn dạ dày nội soi với thời gian phẫu thuật là 150 phút.

Sự phát triển của u ra ngoài thanh mạc hay vào trong niêm mạc cũng là một yếu tố quyết định thời gian mổ. Những u phát triển ngoài thanh mạc sẽ dễ dàng được định vị, xác định diện cắt trong mổ. Những u phát triển vào trong niểm mạc, đặc biệt là các khối u nhỏ sẽ khó định vị hơn, khó xác định chân u cũng như diện cắt tương ứng, do đó sẽ mất nhiều thời gian hơn.

Trong nghiên cứu này của chúng tôi không gặp trường hợp tai biến trong mổ và biến chứng sau mổ. Điêuu này có thể được giải thích do ưu điểm của phẫu thuật nội soi là quan sát rõ các tạng, phẫu trường rộng nên thao tác chính xác hơn, hạn chế được cáćc tai biến. Bệnh nhân được ăn vào ngày hậu phẫu thứ $2-3$. Trung bình thời gian nằm viện sau mổ là $6,02 \pm 1,18$ ngày, ít nhất là 4 ngày với một số bệnh nhân cắt dạ dày bằng stapler, nhiêu nhất là 9 ngày trong trường hợp cắt đoạn dạ dày.

Về hình ảnh vi thể, GIST có thể chia thành 3 dạng chính: dạng tế bào hình thoi, dạng biểu mô và dạng hỗn hợp. Trong nhóm nghiên cứu của chúng tôi, dạng tế bào hình thoi chiếm 35/37 trường hợp (chiếm tỷ lệ 94,6\%), tế bào dạng biểu mô chiếm $5,4 \%$. Tỷ lệ dạng tế bào hình thoi chiếm đa số, kết quả này cũng tương đồng với nhiều nghiên cứu khác: Xanxai Soryavong $80 \%$, In- Hwan Kim 76,6\%

29/37 bệnh nhân được xét nghiệm hóa mô miễn dịch với dấu ấn chính là CD117, CD34, DOG1, SMA, S100, Desmin. 8 bệnh nhân không xét nghiệm hóa mô miễn dịch do kích thước u không to (dưới $5 \mathrm{~cm}$ ), kết quả giải phẫu bệnh trả lời Gist dạ dày độ ác tính thấp, kết quả hoá mô miễn dịch không làm thay đổi phương hướng điều trị tiếp theo của bênh nhân. Trong nghiên cứu, tỷ lệ dương tính CD117 đạt 100\%, DOG1 dương tính $100 \%$, CD34 dương tính 96,6\%, SMA dương tính $17,2 \%$. Kết quả này cũng phù hợp với nhiều nghiên cứu như In- Hwan Kim (2014) tỷ lệ CD 117 cao (chiếm 96,6\%)

\section{KẾT LUẬN}

- Bệnh gặp nhiều hơn ở nữ giới, độ tuổi trên 40 với triệu chứng thường gặp là đau bụng âm ỉ, kéo dài vù̀ng thượng vị.

- Siêu âm ổ bụng không phải sự lựa chọn tối ưu để chẩn đoán GIST

- Nội soi dạ dày và chụp cắt lớp vi tính ổ bụng cần thiết và hiệu quả trongchẩn đoán GIST dạ dày.Hình ảnh tổn thương trên phim cắt lớp vi tính hay gặp: khối đặc, ngấm thuốc mạnh, ranh giới rõ, không xâm lấn, kích thước u từ 2 đến $5 \mathrm{~cm}$. Giá trị sinh thiết kim qua nội soi không cao trong GIST. Siêu âm nội soi dạ dày nên thực hiện khi không rõ u trên phim cắt lớp vi tính

- Không xảy ra tai biến trong mổ và biến chứng sau mổ, thời gian cho ăn lại sớm, thời gian nằm viện ngắn.

Từ các kết quả trên, có thể thấy phẫu thuật nội soi điều trị GIST dạ dày với kích thước dưới $9 \mathrm{~cm}$ là an toàn và hiệu quả và có thể thực hiện ở những trung tâm lớn, phẫu thuật viên có kinh nghiệm.

\section{TÀI LIÊU THAM KHẢO}

1. Đỗ Hùng Kiên. Nghiên Cứu Kết Quả Điều Trị u Mô Đêm Đường Tiêu Hóa (GISTs) Giai Đoan Muônn Bằng Imatinib Tại Bệnh Viện K. Luận án Tiến Sỹ்.; 2017.

2. Bùi Trung Nghĩa. Đánh Giá Đắc Điểm Lâm Sàng, Cận Lâm Sàng và Kết Quả Điêu Trị Phẫu Thuật u Mồ Đệm Đường Tiêu Hóa (GIST) Tại Bệnh Viện Viêt Đức Từ Tháng 01/2005 Đến 12/2010. Luấn văn tốt nghiệp nội trú,. Đại học y Hà Nội; 2011.

3. Canonico B., Felici C. \& Papa S. Cd117.J Biol Regul Homeost Agents.2001:90-94.

4. Yasui H, Konishi E, Urasaki K, Yasukawa S, Yanagisawa A. Intratumoral heterogeneity of MIB-1 labelling index in gastric gastrointestinal stromal tumor (GIST). Gastric Cancer Off J Int Gastric Cancer Assoc Jpn Gastric Cancer Assoc. 2006;9:223-228.

5. Kim M-C, Yook J-H, Yang H-K, et al. LongTerm Surgical Outcome of 1057 Gastric GISTs According to 7th UICC/AJCC TNM System. Medicine (Baltimore). 2015;94(41):e1526.

6. Xanxai Soryavong. Đánh giá kết quá sớm phẫu thuật u mô đệm dạ dày tại bệnh việ̂n Hữu Nghị Việt Đức, Luận văn tốt nghiệp thạc sỹ ngoại khoa, Trường Đai hoc Y Hà Nôi.

7. Phạm Minh Hải. Đặc Điểm Lâm Sàng, Cận Lâm Sàng và Kết Quả Sớm Của Phẩu Thuât Điều Trị u Mô Đệm Đường Tiêu Hóa. Luận văn tổt nghiệp bác sỹ nội trú. Trướng Đại học Y Dược TP Hồ Chí Minh; 2008.

8. Cantor MJ, Davila RE, Faigel DO. Yield of tissue sampling for subepithelial lesions evaluated by EUS: a comparison between forceps biopsies and endoscopic submucosal resection. Gastrointest Endosc. 2006; 64(1):29-34. 